\title{
Kurtide kogukond, viipekeel ja pärimus visuaalsusele toetuvates tehnoloogilistes keskkondades
}

\author{
Liina Paales
}

\begin{abstract}
Teesid: Artiklis käsitletakse kurtide suhtlemist hõlbustavaid tehnoloogilisi võimalusi ning viipekeele ja kurtide pärimuse kohanemist uutes keskkondades. Kuulmismeelele toetuvad abivahendid, mis lähendavad kurti kuulvale enamuskultuurile ja ärgitavad kasutama verbaalset keelt, jäävad kurtide kogukonnas võõra kultuuri artefaktideks. Kurtide kultuuris on omaks võetud visuaalsusele toetuvad tehnoloogiad ja nende loodud keskkonnad, milles viipekeel ja kurtide folkloorne pärimus on leidnud oma loomuliku koha.
\end{abstract}

Märksõnad: Internet, kurdid, kurtide folkloor, kuulmisabivahendid, kuulmispuue, viipekeel, visuaalsed tehnoloogiad

Pimekurt Ameerika kirjanik ja ühiskonnategelane Helen Keller (1880-1968) on öelnud, et nägemispuue eraldab inimese asjadest, aga kurtus kaasinimestest. Seoses uute tehnoloogiliste võimaluste väljatöötamisega võime õnneks tõdeda, et tema ütlus kurtuse kohta ei pea tänapäeval enam paika. Uute seadmete ja infotehnoloogia kasutuselevõtt on kergendanud kurtide igapäevaelu ja hõlbustanud nende suhtlust nii omavahel kui ka kuuljatega.

Käesoleval artiklil on kaks eesmärki: esiteks tutvustada kuulmisabivahendeid, seejärel pisut põhjalikumalt visuaalsusele toetuvaid kommunikatsiooniseadmeid, mis võimaldavad kuulmisvõimetutel inimestel olla ühenduses nii omakeskis kui ka ümbritseva, kuuldava maailmaga ${ }^{1}$; ja teiseks vaadelda kurtidele avanenud eneseväljendus- ja suhtlemisvõimalusi Interneti-keskkonnas.

\section{Kurtide kogukond ja tehnoloogilised valikuvõimalused}

Viipekeelse luule looja ning briti ja ameerika viipekeele uurija Dorothy Miles väidab, et kurtidel inimestel on enesemõistmiseks ühiskonna poolt antud põhimõtteliselt kaks võimalust: meditsiinilistest kriteeriumidest lähtudes saa- 
vad neist mittetäiuslikud kuuljad; kultuurirühmana saavad nad arendada aga kõrgemat enesetunnetust, mille aluseks on oma keel ja traditsioonid. Eelöeldule leidub nii poolt- kui ka vastuargumente, kuid põhimõtteliselt on need kaks levinuimat kurtuse käsitusviisi, mis esitavad ühiskonnale ja viipekeelsele kogukonnale endale erinevad väljakutsed (vt Paavel, Toom 1991: 620-621).

Meditsiinilise suuna toetamisel ja kurtuse kui puude käsitamisel on teistest kuuljatest soodsamas olukorras kuuldetehnika ja meditsiiniala spetsialistid. Kogu ajaloo vältel on otsitud võimalusi parandada kehva kuulmist kas meditsiinilise sekkumisega või kuulmisabivahendite kasutuselevõtuga. Meditsiinitehnoloogia eesmärk on parandada või taastada kuulmisvõime, töötades selleks välja meditsiinilisi lahendusi või abivahendeid.

Tänapäevased kuulmisabivahendid on näiteks digitaalsed kuuldeaparaadid (kõrvasisesed, kõrvatagused ja taskukuuldeaparaadid) ja FM-süsteemid (vt http://www.ead.ee/kurtus.html). Modernseteks võteteks on näiteks sisekõrva proteesi (kohleaarimplantaadi, ingliskeelne lühend CI) kirurgiline paigaldamine ja geeniuuringud.

Kohleaarimplantaat, mida on nimetatud ka kurtide kuuldeaparaadiks, on seni maailmas ainuke aparaat, mis on suudetud funktsionaalselt ühendada närviga. See muudab helisignaalid elektriimpulssideks ja need mõjutavad otseselt närvikiude (Kruustük \& Suurna \& Siirde 2003, vt ka ingliskeelset videot http://www.video.about.com/deafness/Cohlear-Implants.html). Implantaat on kaheosaline. Vastuvõtja on paigaldatud kirurgiliselt kõrva taha ja sealt viivad peened juhtmed otse sisekõrva. Teist osa - mikrofoni ja kõneprotsessorit kantakse kaasas, saatja on paigaldatud kõrva taha. Operatsioon tehakse üldanesteesias ja sellega kaasnevad kõik riskid. Pärast operatsiooni implantaat programeeritakse. Omandatud kuulmine on tehislik.

Enne ja pärast operatsiooni teeb patsient läbi nõustamise, kuuldetreeningud ja kõneteraapia. Sobivateks patsientideks loetakse kuulmispuudega sündinud väikelapsi, aga ka hiliskurdistunud täiskasvanuid. Laste puhul on suundumus teha operatsioon võimalikult vara, isegi kuuekuuselt. See omakorda eeldab kuulmispuude varast diagnoosimist. Oluline on teada, et implanteeritust ei saa imeväel kuuljat, ta jääb siiski kurdiks või vaegkuuljaks ja vajab jätkuvalt toetavat ravi.

Siinkohal on nähtavasti mõistetav, et suhtumine meditsiinilis-tehnoloogilisse edasiminekusse ja selle vastuvõtt on kurtide ja kuuljate maailmas erinev. Kuulev ühiskond näeb meditsiinilistes uuendustes võimalust taastada puuduv kuulmismeel, et selle toel treenida kurtide kõnevõimet ja lõimida neid kuuljate ühiskonda. Kurtide suhtumine implanteerimisse, aga ka teistesse kuulmismeelele toetuvatesse abivahenditesse, millega kaasneb kuulva ühis- 
konna poolt viipekeele eitamine ja kurtide kultuuri mittetunnustamine, on skeptiline, sageli ka tõrjuv.

Kuuldeabivahendite teemat käsitletakse kurtide folkloorses pärimuses humoorikalt, seesugustesse esemetesse suhtutakse tögavalt või peetakse neid lausa ohtlikuks. Toon selle kohta kaks näidet.

Olen kuulnud välismaal elavatelt kurtidelt, et kohlea implantaat ei ole üldsegi ohutu. Kui selline operatsioon on tehtud, siis ei tohi näiteks saunas käia, ujuda ega päikest võtta. Ei ole uurinud, kas see ka tõele vastab. Mulle räägiti üht lugu, et üks kurt, kellele oli see operatsioon tehtud, jäi vanaduses halvatuks, just see näopool, kus see implantaat peas paiknes (Paales 2001b: 157, http://www.ead.ee/utoo3.htm).

Taevas lendavad kaks lindu. Üks lind on lennates kõvasti ühele poole kaldu. Miks? Vastus: lind on kurt. Tal on kuuldeaparaat, selle raskus kisubki ta viltu (EFA I 47, 111).

Järgnev karikatuur illustreerib humoorikat suhtumist kuuldeaparaati. Autor on omistanud esemele koomilise funktsiooni: kuuldeaparaadist on saanud selekteeriv kuuldeaparaat meestele, selle kandja saab valida, kas kuulda oma naise juttu või mitte.

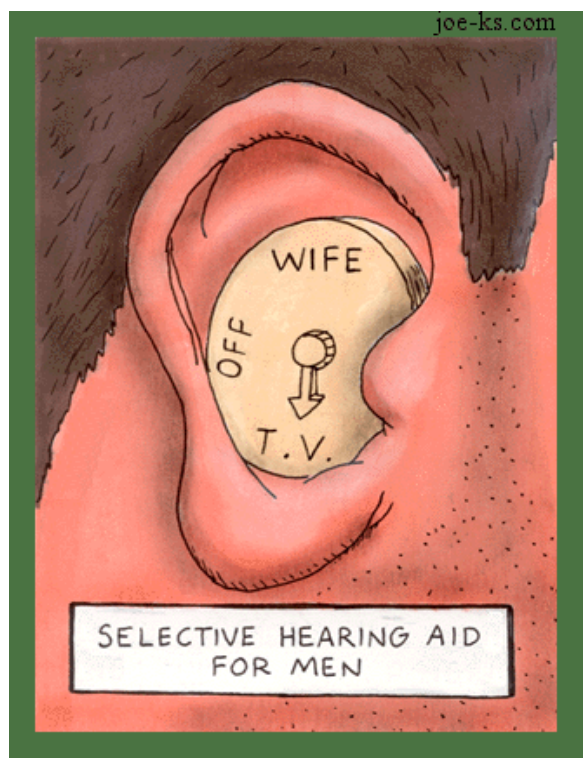

http://www.joe-ks.com/archives_sep2003/HearingAid.gif 
Kurtuse mõistmisel keelelis-kultuurilise nähtusena on eelisseisundis ühiskonnateadlased ja kultuuriuurijad: keeleteadlased, folkloristid, semiootikud, üldisemalt viipekeelt valdavad inimesed. Soositud on kindlasti ka videotehnikatööstus kui kurtide visuaalse keele ja kultuuri jäädvustamise võimaluste looja. Keelelis-kultuurilise suuna esindajate eesmärk on õppida tundma kurtide rahvuslike kogukondade ajalugu, kultuuri ja viipekeeli ning tutvustada ja väärtustada kurtide pärandit kui enamuskultuuri rikastavat nähtust.

\section{Viipekeelse kogukonna suhtlust toetavate seadmete arengust}

Kurte toetavatest tehnilistest abivahenditest kõneldes ei saa mööda isikust, kes on oluline nii kuuljate kui kurtide inimeste ajaloos - nimelt Alexander Graham Bellist (1847-1922). Et mõista paremini selle mehe valikuid ja püüdlusi kurtuse likvideerimiseks, on abiks teadmine, et nii tema emal kui ka abikaasal oli kuulmispuue. See tõsiasi mõjutas kogu A. G. Belli eluteed, nii ametialast kui ka isiklikku elu (Woolley 2000: 24; http://en.wikipedia.org/wiki/ Alexander_Graham_Bell).

A. G. Bell kogus kuulsust telefoni leiutamisega aastal 1876. Tegelikult tahtis ta aga luua aparaati, mis võimaldaks kuulmisvõimetutel inimestel õppida rääkima. Kahjuks oli tema töö tulemus hoopis midagi muud - telefonist, mis oli ülemöödunud sajandil üks tähtsaimaid kommunikatsioonilisi uuendusi, kujunes ese, mis lahutas kuuljaid ja kurte. Viimased ei saanud kuulmismeelele toetuvat telefoniaparaati kasutada. See ettevõtmine kahandas A. G. Belli mainet Ameerika kurtide seas tunduvalt: nimelt ei ole ta sealses kurtide pärimuses kuigi populaarne.

Telefonitehnoloogia oli peaaegu sada aastat kurtide kogukonnale kättesaamatu. 1960. aastatel hakati Ameerika Ühendriikides kasutama nägemismeelele toetuvaid tekstitelefone, mida mitmed ettevõtted võtsid tootmisse 1970. aastatel (http://en.wikipedia.org/wiki/Telecommunications_devices_for_the_deaf).

Tekstitelefoni vahendusel suheldakse kirjalikult, see on spetsiaalselt kurtidele mõeldud elektrooniline seade (ingl $\mathrm{k}$ telecommunications device for the deaf, lühendatult TDD) teksti edastamiseks mööda telefoniliine, seadmel on ka teisi nimetusi: teletaip (inglise $\mathrm{k}$ telephone typewriter, teletypewriter, lühend TTY), tekstofon (ingl k textphone, seda nimetust kasutatakse harilikult Euroopas ja Ühendkuningriigis), minicom (Ühendkuningriigis). Eestis on kurdid tekstitelefone kasutanud vähe ja üsna lühiajaliselt - tegemist oli vähestele kättesaadava eksklusiivtootega. Tekstitelefonide teema kajastub ka kurtide folklooris: 
Kolm maja asetsevad üksteisest pisut eemal. Majade kohal on elektritraadid. Elektritraatidel istuvad linnud. Kahe maja kohal istuvad linnud on rahulikud, istuvad vagusi. Kolmanda maja kohal istuvad linnud on närvilised, muudkui astuvad jalalt jalale. Miks?

Vastus: Selles majas, mille kohal istuvad linnud on närvilised, elab kurt. Ta muudkui toksib - toks-toks - oma tekstitelefonil - seepärast astuvadki linnud jalalt jalale (EFA I 47, 111).

Väga oluliseks kujunes 1970. aastatel videotehnika areng, mis võimaldas salvestada viipekeelset teksti. Eelkirjeldatud uuendused on olulised kahel põhjusel: tekstitelefonid andsid kurtidele esmakordselt võimaluse suhelda omavahel suure vahemaa tagant, videotehnika lubas aga talletada omakeelset teksti.

Eestis kasutasid kurdid 1990. aastate alguses suhtlemiseks nii omavahel kui ka kuuljatega faksiaparaate ja vähem piipareid. Edaspidi osutus kiiremaks ja mugavamaks suhtlemine mobiil- ja arvutiside vahendusel. Mobiiltelefoni puhul kasutavad kurdid lühisõnumi saatmise võimalust. Mõnikord on kurtide ja kuuljate ühises seltskonnas tekitanud hämmingut küsimus, milleks vajab kurt mobiiltelefoni. Kuuljal ei seostu taskutelefon kõigepealt lühisõnumite saatmise võimalusega, vaid ikka kuuldelise suhtlusega. Praegu on enamasti mobiilitelefoni sisse ehitatud vibreeriv alarm, mis on kurtidele mugav signaal sõnumi saabumise kohta. Mobiiltelefonide lühisõnumiteenuse kasutamine kurtide poolt on huvitav näide sellest, kuidas algselt sihtrühmaks mitte planeeritud kogukond avastab endale sobiva kommunikatsioonilahenduse ja rakendab seda oma argipäevases suhtluses. Praeguseks on mõned mobiilsideoperaatorid seda juba taibanud ning pakuvad spetsiaalselt kurtidele suunatud soodsaid lühisõnumi pakette.

Arvutiside puhul kasutavad kurdid nii elektronposti kui ka MSN Messengeri. Suurbritannias on loodud omalaadne tarkvara eSIGN, virtuaalne viipleja Guido, mis tõlgib veebilehed viipekeelde. Virtuaalne viipleja aitab kurtidel, kelle esimene keel on viipekeel, informatsiooni kiiremini kätte saada. Täiesti uudne võimalus on kurtide kogukonnale arvuti vahendatud visuaalne telefonitehnoloogia. Ühendades veebikaamera arvutiga saavad viipekeelsed inimesed üksteisega suhelda internetis tavatelefoni liinide kaudu. See on murrangulise tähtsusega, sest kurtidele avaneb sellega võimalus suhelda viipekeeles pikkade vahemaade tagant. Kommunikatsiooni edukaks toimumiseks peavad vestluskaaslased jälgima, et on ise nähtaval ja näeksid ka oma kaaslast.

Seesugust uut tehnoloogiat rakendatakse ka viipekeele tõlketeenuses. Nimelt saavad niiviisi omavahel suhelda ka viipekeelt mittevaldav kuulja ja kurt, 
kusjuures suhlemine toimub viipekeeletõlgi vahendusel. Selleks on välja arendatud kaks erinevat telekommunikatsioonipõhist teenuseliiki.

Esiteks Video Remote Interpreting (lühendatult VRI), mille puhul viipekeeletõlk ei asu kuulja ja kurdi suhtluspartneriga samas kohas (http:// en.wikipedia.org/wiki/Video_Remote_Interpreting). Tavapärane VRI situatsioon on järgmine. Kurt ja kuulja asuvad samas kohas, seal asub ka kaamera ja teleekraan; viipekeeletõlk on teises paigas - enamasti tõlkekeskuses -, kus on samuti kaamera ja teleekraan. Mõlemad kaamerad võimaldavad video- ja audioühendust ning viipekeeletõlk hõlbustab samas kohas oleva kurdi ja kuulja omavahelist suhtlemist. Eemalasuv tõlk kuuleb kõnelevat isikut, kelle jutu ta tõlgib viipekeelde, mida kurt isik näeb omakorda teleekraanilt. Sama toimub ka vastupidi: kurt isik viipleb kaamerasse ja tõlk näeb, mida öeldakse, ning tõlgib viibeldu kuuljale kõneldavasse keelde (vt järgnevat fotot, pärit http://www.sorensonvri.com).

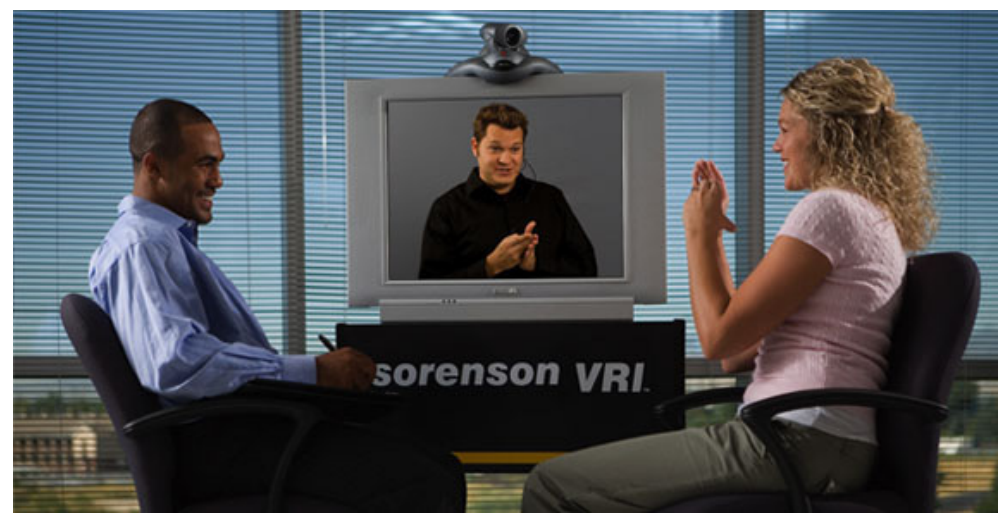

Teiseks teenuseliigiks on Video Relay Service, mille eripära seisneb selles, et kõnelejast ja viiplejast suhtluspartnerid võivad asuda erinevas paigas ja saavad tõlgi abil omavahel suhelda telefoniliinide kaudu (http://en.wikipedia.org/ wiki/Video_Relay_Service). Esiteks viipleb kurt videokaamera (see on ühendatud kas televiisori või arvutiga) kaudu oma sõnumi viipekeeletõlgile, mille viipekeeletõlk tõlgib kõneldavasse keelde ja vahendab telefonikasutajale. Telefoniga rääkija vastab ja viipekeeletõlk tõlgib tema vastuse viipekeelde (vt fotot http://www.sorensonvrs.com/what/index.php). Seesugune suhtlemine on palju sujuvam ja võtab vähem aega kui näiteks suhtlemine trükitud teksti kaudu tekstitelefoni puhul. 


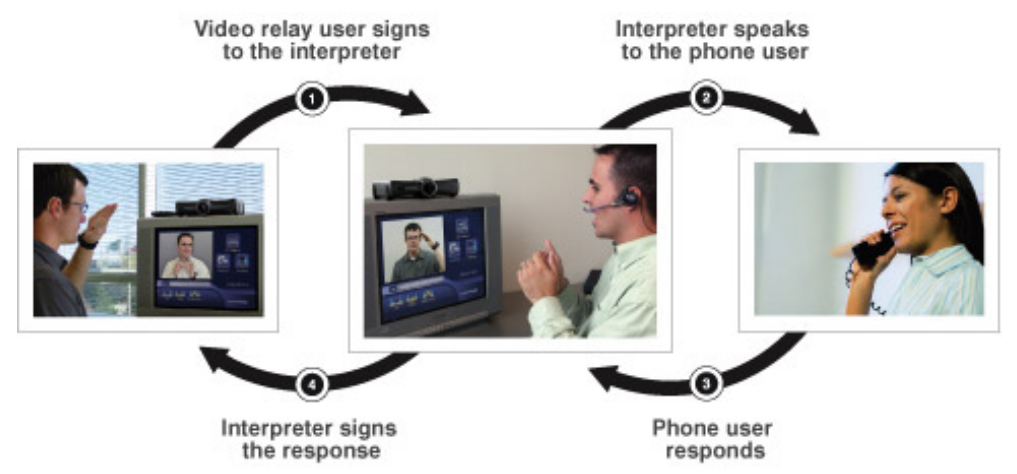

Kui mobiilikaudne lühisõnumite saatmine on kurtide puhul juba igapäevane, siis omavaheline viipekeelne suhtlemine mobiiltelefonitsi on alles uudne. Viipekeelset suhtlemist võimaldavad alates 2000 . aastate algusest uued $3 \mathrm{G}$ videofonid. Eelkirjeldatud võimalust püütakse näiteks Soomes rakendada viipekeele tõlketeenuses. Seesugune tõlkesituatsioon on sarnane eelpool kirjeldatud VRIga, kus kurt ja viipekeeletõlk asuvad erinevates kohtades. Tõlk näeb oma videofonis kurti klienti ja kurdiga samas ruumis olev kuulja kuuleb videofonis tõlgi häält. 3G videokõnesid viipekeele tõlketeenuses kasutatakse veel Rootsis ja Jaapanis (http://www.mobiilitulkki.fi). Eestis ei ole eelkirjeldatud teenuseliikide otstarbekuse uurimise, testimise või arendamisega veel tegeldud.

Ameerika Ühendriikides, kus on telekommunikatsiooni rakendamisel nii kurtide omavahelises kui ka kuuljatega suhtlemises aastatepikkused kogemused, on ilmunud ka esimesed uurimused ameerika viipekeelest uutes kasutusalades. Näiteks on käsitletud kurdi inimese viiplemise iseärasusi virtuaalses suhtlemissituatsioonis (Keating \& Mirus 2003).

\section{Kurtide kogukondade esindatus internetis. Eesti kurtide organisatsioonide koduleheküljed}

Internetis on rikkalikult esindatud igasugused sektid ja vähemusrühmad. Netikeskkond on kättesaadav ja demokraatlik, avatud vabaks eneseväljenduseks. See on suurepärane enese nähtavakstegemise võimalus nendele, kes on varasemas traditsioonilises meedias tagaplaanil olnud (vt Runnel 1999: 17; Lintrop 2000: 112). Ka kurtidele inimestele on virtuaalmaailm muutunud kergesti kättesaadavaks ja sobivaks keskkonnaks, mille visuaalsus toetab nende keelt ja kultuuri. Teisest küljest võimaldab internet kuuljatel kurtide elulaadist roh- 
kem teada saada, kasvatada teadlikkust viipekeelse kogukonna suhtes ja ehk aidata vähendada ka eelarvamusi.

Netiavarustes leidub rikkalikult allikaid, mis kajastavad sõnas ja pildis kurtuse olemust, kurtide ja nendega seotud organisatsioone, kurtide tegevusi ja loomingut jne. Ühelt poolt on kurdid virtuaalmaailmas esindatud oma formaalsete ühenduste kodulehekülgede kaudu, teiselt poolt võivad nad olla kaasatud erinevatesse kommuunidesse, mille liikmete omavaheline suhtlemine põhineb kirjutatud tekstil. Seega on suhtlemine võimalik ka nii, et kurtus jääb varjatuks.

Järgnevalt tutvustan Eesti kurtide ja kurtidega seotud organisatsioonide kodulehekülgesid. Eesti Kurtide Liit (EKL) on Eestis elavate kurtide esindusorganisatsioon, millel on omad piirkondlikud ühingud. EKL lehel http:// www.ead.ee tutvustatakse kurtuse olemust, organisatsiooni ajalugu ja eestikeelseid kurtusealaseid uurimusi. Leidub ka muud üldhuvitavat infot ja viiteid teistele asjaomastele lehekülgedele.

Oma lehekülg (http://www.thky.ee) on Tallinna ja Harjumaa Kurtide Ühingul. See pakub kurtidele mitmekülgset infot, lisaks leidub seal ka südamlik jutt konnast, kes tänu kurtusele saavutas oma eesmärgi (http://www.thky.ee/ et/varia/konn). Sümboolne lugu on mõeldud julgustama kurte inimesi - kuuljate maailmas on võimalik hakkama saada.

Piirkondlikest kurtide ühingutest on oma kodulehekülg veel Pärnumaa kurtidel (http://www.parnu-kurdid.ee). Lehel tutvustakse ühingu ajalugu, edastatakse päevakajalist infot, hoitakse fotoalbumit ja kajastatakse kogukonna koostegemisi ja ettevõtmisi.

Eesti Kurtide Spordiliidu (EKSL) kodulehel (http://www.kurtidespordiliit.ee) tutvustatakse organisatsiooni ajalugu, avaldatakse eri spordialadel võistlejate tulemuste edetabeleid ja teavitatakse eesolevatest võistlustest.

Kurdid noored on koondunud Eesti Kurtide Noorte Organisatsiooni (EKNO) ja tutvustvad oma tegemisi aadressil http://www.ekno.ee. Kristlikke evangeelseid kurte ühendab Eesti Kristliku Nelipühi Kiriku kurtide kogudus, mille tööharude kohta saab lugeda veebiaadressilt http://www.deafestonia.org.

Oma koduleheküljed on mitmel kurtidega seotud organisatsioonil. Eesti Viipekeele Tõlkide Ühenduse (http://www.evkty.ee) veebikodus antakse ülevaade ühingu ajaloost, viipekeeletõlgi kutse kujunemisest Eestis, seal leidub ka atesteeritud tõlkide register ja muud kasulikku teavet.

Eesti Kuulmispuuetega Laste Vanemate Liidu (http://www.eklvl.ee) kodulehel leiduv materjal on suunatud eelkõige peredele, kus on kasvamas kurt või vaegkuulja laps. Lugeja leiab teavet kuulmispuudega lapse haridusvõimaluste kohta ja saab tutvuda erinevate õpetamismeetoditega. 
Samuti on oma internetikodud kurtide haridusasutustel. Tartu Hiie Kooli (http://www.hiie.tartu.ee) veebilehel saab teada kooli ajaloost, edastatakse jooksvat infot, tutvustatakse uusi hariduslikke projekte ja muud koolieluga seonduvat.

Tallinna Heleni Kooli (http://www.helen.tln.edu.ee) lehekülg annab samuti ülevaate õppeasutuse kujunemisloost, koolielust, õpilaskonnast, kelle moodustavad kuulmis- või nägemispuudega lapsed ja tavaõppurid. Nagu teistelgi organisatsioonidel, leidub ka siin oma pildigalerii ja lingid teemalähedastele veebilehekülgedele. Huvipakkuv on videoklipp viipekeelse Eesti Vabariigi hümniga.

\section{Internet kurtide pärimuskeskkonnana ameerika viipekeelse folkloori näitel}

Internet kurtide pärimuse keskkonna ja uurimisvaldkonnana on küllaltki uus nähtus (vt Runnel 1999). Ka virtaalmaailmas leiduva kurtuseteemalise pärimusaine saab jagada kogukonnast endast lähtuvaks teabeks ja enamuskultuuri ehk siis kuuljatepoolseks kurtuse käsituseks (nt kurtuseteemalised ja viipelise kommunikatsiooni kohta käivad anekdoodid ja naljad kuuljate folklooris). Eristavaks teguriks on vaatenurk kurtusele, mis viipekeelsete inimeste puhul on positiivne ja loomulik.

Järgnevalt peatun mõnel subjektiivselt valitud veebiallikal, mis esitavad kurtide pärimust viipekeelest kõneldavasse keelde tõlgitud tekstide, viipekeelsete videokatkete, animatsioonide ja karikatuuridena.

Kurtide jutupärimus ja muud liigid. Internetis leidub rikkalikult viipekeelest verbaalsesse keelde tõlgitud kurtide anekdoote, nalju, kogemusjutte, aga ka muud pärimust, andes viipekeelt mittevaldavale inimesele suurepärase võimaluse heita pilk kurtide folkloorile ja laiemalt võttes olla kurtide kultuuri vastuvõtja.

Kui internetis leiduv info on peaasjalikult ingliskeelne, siis kurtide pärimuse puhul domineerib ameerika viipekeelest inglise keelde tõlgitud materjal. ${ }^{2}$ Seega saame veebikeskkonnas põhiliselt aimu Ameerika kurtide kogukonna folkloorist. Sisestades otsisõnadena näiteks deaf jokes, deaf anecdotes, deaf humor võib sattuda rikkalikule kurdiliku algupäraga pärimusele (vt Paales 2001: 143-145). Uurides ise Eesti kurtide kogukonna folkloori ${ }^{3}$ rõõmustasin veebikeskkonnast leitud eri jututüüpide variantide üle, mis esinevad ka eesti viipekeelses pärimuses. Järgnevalt mõned valitud näited virtuaalkeskkonnast leitud juttudest. 
Esimeses loos on tegelasteks Jumal, kurt mees ja kuulja mees. Kuulja mees loovutab kurdile oma eesõiguse kolmele soovile. Kurt oskab pöörata olukorra endale väga kasulikuks.

The Earth was totally destroyed by nuclear warfare, and there were two survivors left. The two survivors were a Deaf man and a Hearing man. Both met in the middle of the destruction and they were trying to communicate. All of the sudden, there was a light from the sky coming closer and there is God. The men were amazed and looked at each other to make sure if the image of God is actually real.

God spoke, "Congratulations! You are the only first person to ask for three wishes and these wishes will be granted to the first person; however the second person will get this same wish doubled." A hearing man thought about it, then said to the Deaf man, "Well, I think that with the unfortunate disability you have, I will let you to be the first person to ask for three wishes." The Deaf was bit surprised and elated, then he pondered what are the things he could wish for...

He signed, "God, I wish I could have four huge houses." God gave four houses to Deaf man and then he also gave eight houses to hearing man. The deaf man saw that and he was not that thrilled about it. Then he thought of the second wish, "God, I want 200 Deaf women, please." God, of course, gave him 200 Deaf women and then another 400 Deaf women for the hearing guy. Then the Deaf man spent time thinking... and finally he has an idea. He signed, "God, I would like for you take one of my testicles, please." God took one away, and... God also took two from a hearing guy... So, the Deaf man said... "Yeah! Now, I will have a Deaf World!"

[Maa oli tuumasõjast täielikult laostatud ja ellu olid jäänud vaid kaks inimest - kurt ja kuulja. Mehed kohtusid kõige selle hävingu keskel ja üritasid suhelda. Äkki langes taevast maa peale valgus ja jumal ilmutas end. Kurt ja kuulja vaatasid teineteisele üllatunult otsa, et veenduda, kas jumala ilmutus on ikka tõeline.

Jumal lausus: "Õnnitlen! Te olete ainsad ja esimesed inimesed, kes võivad soovida kolm soovi, ja esimese soovid täituvad. Teisena soovijal täituvad aga samad soovid kahekordselt.” Kuulja mõtles selle üle ja ütles siis kurdile: "Niisiis, kuna sinul on tõsine puue, siis luban sul esimesena soovida need kolm soovi." Kurt oli mõnevõrra üllatunud, kuid rõõmustas selle üle. Siis aga hakkas arutlema, mida ta võiks endale soovida. Ta viiples: "Jumal, ma soovin, et mul oleks neli hiiglasuurt maja." Jumal andis neli maja kurdile ja samas kaheksa maja kuuljale. Kurt 
nägi seda, ega olnud selle üle kuigi rõõmus. Siis soovis ta teise soovi: "Jumal, ma soovin, et mul oleks kakssada kurti naist." Jumal muidugi andiski talle kakssada kurti naist ja ka nelisada kurti naist kuuljale mehele. Siis kurt mõtles veidi ja lõpuks tuli talle hea mõte. Ta viiples: "Jumal, ma soovin, et sa võtaksid ühe mu munadest." Jumal võttiski ühe kurdilt... ja kaks kuuljalt mehelt. Seal ütleski kurt: "Tore! Nüüd saan ma elada kurtide maailmas!"]

(Jokes - http://www.deafworldweb.org/pub/j/joke.more.html)

Teine tekst toob hästi esile viipekeelse kommunikatsiooni visuaalse eripära. Jutus võimendub nägemismeele olulisus kurtide kommunikatsioonis. Mida hoogsamalt ja laiemalt viibeldakse, seda "valjem" see on. Ilmselt on selles loos ka vihje pimekurtide kommunikatsioonile, nimelt toimub sel juhul taktiilne viiplemine ehk viibeldakse niiöelda käsikäes.

I noticed a deaf couple in the library talking to each other, evidently in a heated argument. The wife was getting more upset, using large signs, her husband could see that she is upset. Finally, he took both her hands in his, and signed, "Honey, you don't have to yell, I am not blind!"

[Märkasin raamatukogus kaht kurti ägedalt viiplemas. Naine ärritus üha enam ja kasutas suuri viipeid ning ta abikaasa sai aru, et naine on ärritunud. Lõpuks võttis ta naise käed oma kätte ja viiples: "Kullake, sul pole vaja karjuda - ega ma pime ole!"]

(Jokes - http://www.lifeprint.com/asl101/pages-layout/jokes.htm)

Kolmandas loos on tegelasteks pime mees, ratastoolis mees ja kurt mees. Jutus tuleb selgesti esile, kuivõrd oluline on kurtidele oma kogukond ja selle liikmete omavaheline kokkuhoidmine. Kurtide kultuurile on omane kollektiivsus, esiplaanil on ühised huvid.

One day a blind man goes to a barber for a haircut. After the cut he asks the barber about his bill. "I am sorry, I cannot accept money from you I am doing community service for handicapped this week." The blind man is pleased and leaves the shop.

The next morning when the barber goes to open his shop, there is a thank you card and a dozen roses waiting at his door.

Later a man in wheelchair comes in for a haircut and he also goes to pay the barber, and the barber replies: "I am sorry I cannot accept money from you. I am doing community service for handicapped this week." The wheelchair man is happy and leaves the shop. 
The next morning the barber goes to open his shop, there is a thank you card and a box of dozen muffins waiting at his door.

A Deaf man goes for a haircut and when he asks barber what he owes, the barber wrote on paper: "I am sorry I cannot accept money from you. I am doing community service for handicapped this week." The deaf man is very happy and leaves.

The next morning when the barber goes to open his shop, a dozen deaf people are lined up waiting for free haircut.

[Ühel päeval läks pime mees habemeajaja juurde juukseid lõikama. Kui juuksed lõigatud, küsib pime habemeajajalt arvet. "Kahjuks ei saa ma teilt raha võtta, kuna teen sel nädalal ühiskondlikult kasulikku tööd puuetega inimeste abistamiseks." Pime mees lahkub habemeajaja juurest rahulolevalt.

Järgmisel hommikul, kui habemeajaja asub oma äri avama, leiab ta ukselt tänukaardi ja kaksteist roosi.

Hiljem tuleb habemeajaja juurde ratastoolis mees, kes palub endal juukseid lõigata. Ka tema pakub habemeajajale raha, mille peale viimane vastab samuti: "Kahjuks ei saa ma teilt raha võtta, sest teen sel nädalal ühiskondlikult kasulikku tööd puuetega inimeste abistamiseks." Ratastoolis mees lahkub rõõmsalt.

Järgmisel hommikul, kui habemeajaja asub oma äri avama, leiab ta ukselt tänukaardi ja kaksteist koogikest.

Ka kurt läheb juukseid lõikama ja kui ta küsib habemeajajalt arvet, kirjutab viimane talle sedelile: "Kahjuks ei saa ma teilt raha võtta, kuna teen sel nädalal ühiskondlikult kasulikku tööd puuetega inimeste abistamiseks." Kurt lahkub väga rõõmsalt.

Järgmisel hommikul, kui habemeajaja asub oma äri avama, leiab ta uksel ootamas kaksteist kurti, kes soovivad tasuta juukselõikust.] (Jokes - http://www.lifeprint.com/asl101/pages-layout/jokes.htm)

Viimane näide kirjeldab, kuidas kurt tõlgendab kuulja inimese käitumist oma vaatevinklist positiivselt, saamata aru, et viimase käitumine on ajendatud kurdi võimetusest kontrollida heli ja kuulja tegelik reaktsioon on hoopis negatiivne.

There was this deaf man who was driving home from work. As he arrived to his neighborhood, he noticed that people were waving at him as he drove by. All the way through his neighborhood, every single person was waving at him. When he finally got home, he got out of the car to see his wife standing at the door waiting for him. "Honey, you're not gonna belive 
this! Everyone is really friendly today! They waved at me the whole time I drove through the neighborhood!" said the man. The wife replied, "No, your horn's stuck."

[Kord sõitis kurt töölt kodu poole. Kodule lähemale jõudes märkas ta, et kõik möödujad lehvitasid talle. Terves ümbruskonnas lehvitas talle iga viimane kui inimene. Kui kurt lõpuks koju jõudis, astus ta autost välja ja nägi naist uksel ootamas. "Kallis, sa ei usu, mis minuga täna juhtus! Kõik on täna nii sõbralikud! Terve selle aja, mil ma sõitsin kodule lähemale, inimesed muudkui lehvitasid mulle," rääkis mees. Naine vastas: "Üldse mitte! Sul on signaal peale jäänud."]

(Bar-Tzur, David. Humor and stories for interpreters: General Deaf humor and musings - http://www.theinterpretersfriend.com/misc/humr/ gdh.html)

Netis leidub ka kurtide jutustajate viipekeeles esitatud anekdoote ja muid lugusid (vt nt http://www.deaffunnyvideos.com).

Kurtide märgipärimus (inglise k signlore) ehk keelehuumor. Märgipärimus toetub viipekeele grammatilistele iseärasustele ja sellest arusaamine eeldab mitte ainult viipekeele valdamist, vaid ka kurtide kultuuri tundmist laiemalt. Seesugust keeleloomingut on võimalik esitada videoklipina.

Viipenimed. Internetist leidsin allika, kus selgitatakse ameerika viipenimede (isikuid ja kohti tähistavad viiped) loomist ja tuuakse näiteid videolõikudena (vt ASL Name Signs - http://www.handspeak.com/byte/ns/). Eesti viipenimede kohta leiab netist illustratsioone E-väljaandes Lemmeleht. Pro folkloristica IX (Paales 2002).

Sõrmendviiped. Üks armastatuimaid keeleloomingu objekte on ameerika viipekeeles väljend ma armastan sind (inglise $\mathrm{k}$ I LOVE YOU ehk ILY-viibe), mis sooritatakse järgmiselt: keskmine sõrm ja sellest järgmine sõrm on surutud rusikasse, pöial, nimetissõrm ja väike sõrm on püsti. Nimetatud viipe aluseks on fraasi moodustavate sõnade algustähed I (I), L (love) ja Y (you) ja nende vasted ameerika sõrmendtähestikus ehk siis väike sõrm on $I$, nimetissõrm ja ja pöial $L$ ning pöial ja väike sõrm $Y$.

Folklorist S. J. Carmeli andmetel on see viibe pärit 1895. aastast või veelgi varasemast ajast (Carmel 1996: 199). Nimetatud viibe on muutunud rahvusvaheliseks, seda kasutavad eri maade kurdid - aga ka kuuljad kui viipekeelsete inimeste ühtehoidmise ja -kuuluvuse tähist. 


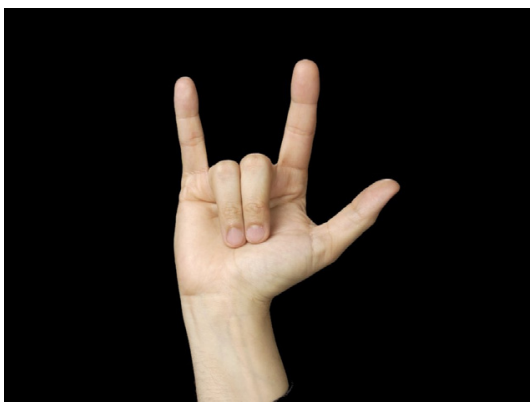

http://www.lifeprint.com/asl101/images-signs/ i_love_you.jpg

http://www.iwatchstuff.com/images/2006/06/ spiderman-3-poster.jpg

Muutes viipe moodustusühikuid, omandab märk erinevaid humoorikaid tähendusvarjundeid. Vahetades ILY-viipes nimetissõrme keskmise sõrmega, tähendab see I always love you (ma armastan sind alati);

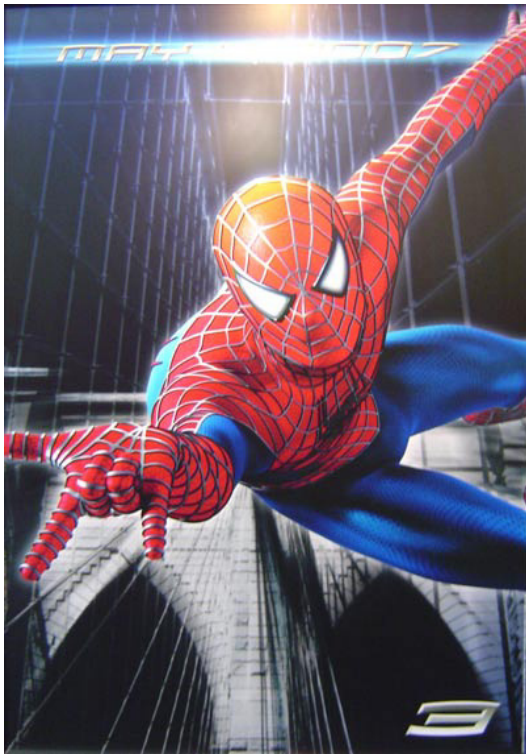
kui nipsutada paar korda nimetissõrme, mida saadab küsimust markeeriv näoilme (kergitatud kulmud), siis tähendab see Do you love me? (Kas sa armastad mind?) jne.

Kurdid on varmad leidma analooge oma keelele ja kultuurile ka ümbritsevast kuuljate maailmast. Nii näiteks omistatakse ILY-viipe kasutamist popkultuurist tuntud Ämblikmehele (vt illustratsiooni http:// www.iwatchstuff.com/images/2006/06/ spiderman-3-poster.jpg). Sama viibe animeerituna Ämblikmehe esituses asub leheküljel http://www.theinterpretersfriend.com/ misc/humr/df-crtuns2.html.

Nii viipenimede kui ka teiste märgipärimuse liikide kohta leidub internetis ka lihtsalt sõnalisi kirjeldusi, mida mõnel puhul toetavad illustratsioonid või animatsioonid (vt nt

Deaf Humor - http://www.lifeprint.com/asl101/pages-layout/humor.htm,

Namesigns - http://www.lifeprint.com/asl101/pages-layout/namesigns.htm).

Sõrmendtähestikulood. Inglise keeles nimetatakse sõrmendtähestikul baseeruvaid lugusid ka $A B C$ stories, alphabet stories, A-to-Z stories. Tähestiku- ehk ABC-lugu on lühike narratiiv, mille struktuur on kristalliseerunud. Jutt koosneb enamasti 25 viipest, millest igaüks sooritatakse ühe käega. Jutt ehitub seega üles tähestikulises järjekorras esitatud sõrmenditest, mis järgivad teatud süžeed. Niisugune lugu on stereotüüpiline ja staatiline, kuid andekate jutustajate jaoks produktiivne vorm.

Eelöeldut illustreerib näiteks tähestikulugu suitsetajast-kimujast, mille esitab Ken Glickman (vt "Pot" - An ABC Story by Ken Glickman. - http:// 
www.youtube.com/watch?v=SC23a548cjA\&NR). Lugu on dubleeritud ka verbaalsesse inglise keelde. Samas leidub kauboide-teemaline tähestikulugu (vt ASL ABC Story! - http://www.youtube.com/watch?v=qj1MQhXfVJg\&feature= related), mille puhul on järjestikuste sõrmendite jälgimise hõlbustamiseks lisatud viiplemisele vastav täht (nt A, B jne). Väga ilmekas näide ABC-lugude varasalvest on jutt auruvedurist, mis on ameerika sõrmendtähestiku mittetundjatele mõeldes varustatud jutustaja kommentaaridega ja loo süžeed selgitavate illustratsioonidega (vt ABC Story Steam Engine by Wonsuk Chung http://www.youtube.com/watch?v=OfiFlhnJMCk\&feature=related).

Numbrilood (inglise keeles numberstory, 1-2-3 story) on olemuselt sarnased tähestikulugudega, ainult et nüüd moodustavad viipeid numbreid tähistavad käeasendid. Numbrilugude kohta leidub internetis sportautode võidusõidu teemaline lugu (vt http://www.youtube.com/watch?v=SZGj-mMEjrs\&feature=user).

Kurtide pildiline veebihuumor. Ameerikas on käsitletud kurtide folkoori all ka muid nähtusi - kurtide joonistatud karikatuurid, viipepoeesia jms, mida Eestis ei ole traditsiooniliselt rahvaluuleks peetud. Kurtide pildiline veebihuumor käsitleb kõverpeeglis kurtide suhteid kuuljate, aga ka teiste puuderühmade esindajatega, kurtuse vääritimõistmist kuuljate poolt ja kurdiksolemise eri tahke argielus.

Järgnev karikatuur esitab tragikoomilise ja ülevõimendatud situatsiooni kurtide ja pimedate inimeste suutmatusest kontakteeruda: valge kepiga pime inimene ei näe ohtu ja rõhutatult arhaistliku terminiga (kurttummade kool) tähistatud bussis olevad õpilased ei saa talle ka märku anda.

Palju leebema olukorra toob meie ette järgmine karikatuur, kus pimedad lauljad, lootuses kolida majja ja riputada uksele silt "kodu pimedatele jõulukoraalide lauljatele", ei näe, et maja on hõivanud juba kurdid.

http://www.deaf4life.co.uk/forum/lofiversion/ index.php/t1216.html

http://www.deafjoke.tv/wp/wp-content/uploads/ 2006/09/deaf_blind.jpg
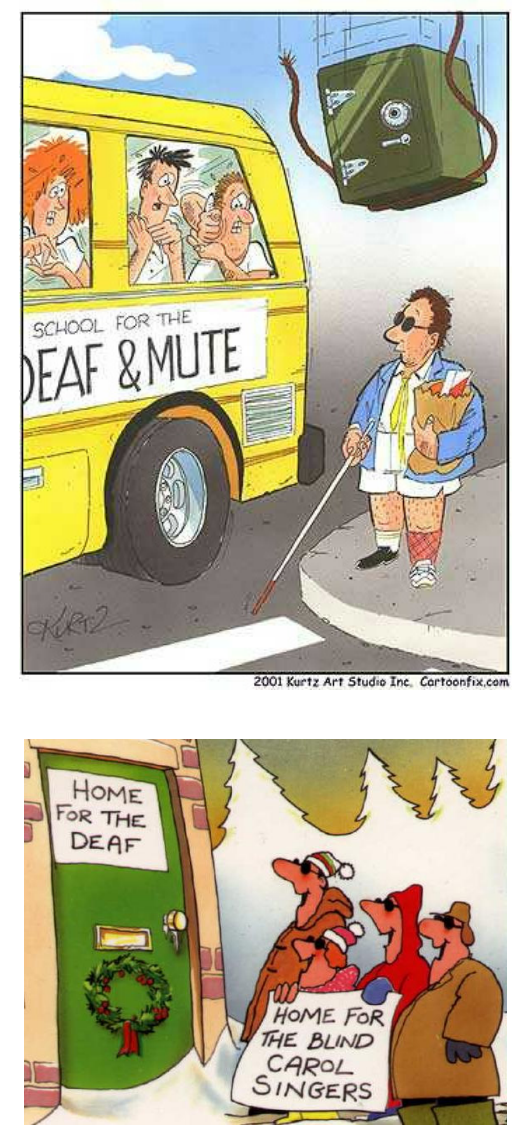
Ülevaate kurtidest karikaturistidest, nende loomingust ja selle avalduskohtadest netimaailmas on teinud J. Berke (vt http://www.deafness.about.com/od/ deafculture/a/deafcomics.htm). Kurtide kultuurilisi eripärasid peegeldavaid karikatuure leidub veebiaadressil http://www.mdaigletoons.com/index.html. Mitmekesine on David Bar-Tzuri koostatud materjal Humor and stories for interpreters: The world of Deaf humor leheküljel http://www.theinterpreters friend.com/misc/humr/world-of-deaf.html. Kurtuseteemalistes karikatuurides sõltub vaatenurk kuulmisvõimetusele sellest, kas autor on ise kurt (kurdiksolemine on igapäevane tõsiasi) või kuulja (kurdid on teistsugused, mitte nagu meie).

\section{Kokkuvõte}

Kurtide kogukondade arengus on toimunud viimastel aastakümnenditel suured muutused. Ühelt poolt on selles oma osa infotehnoloogia ja telekommunikatsiooni vahendite väljatöötamisel, mis toetavad edukalt kurtide visuaalset kultuuri ja lähendavad seda oma tekstilis-pildiliste infoedastusvõimalustega kuulvale ühiskonnale; teisest küljest on muutuma hakanud ka mentaalsus, mis ei näe kurtuses enam üksnes puuet.

Uudne võimalus kurtide kogukondadele on arvuti vahendatud visuaalne telefonitehnoloogia. Ühendades veebikaamera arvutiga saavad viipekeelsed inimesed suhelda üksteisega interneti vahendusel tavatelefoni liinide kaudu. See on murrangulise tähtsusega areng, sest kurdid saavad üksteisega suhelda viipekeeles pikkade vahemaade tagant.

Kurdid saavad paremini lõimuda kuulvasse ühiskonda, mis tunnustab viipekeelt ja on teadlik kurtide kogukondade omakultuurist. Selle väljenduseks on riikliku viipekeele tõlketeenuse väljaarendmine, viipekeeletõlkide koolitamine, kurtide kultuuri ja viipekeele uuringute toetamine ning kogukonna omakultuuri väärtustamine.

Viipekeelsed kogukonnad on endale avastanud virtuaalkeskkonna, nad on seal mitmekülgselt esindatud ja kasutavad seda oma eesmärkide ja vajaduste täitmiseks. Kurtide folkoor on internetis kättesaadav ja erineval moel esitatuna, kas siis verbaalsesse keelde tõlgituna, videoklippidena või pildilisel kujul, ligipääsetav ka viipekeelt mittevaldavatele inimestele.

Me ei tea, milliseid võimalusi pakub verbaalses ja viipekeeles suhtlejatele tulevik - selle üle saame fantaseerida. Tuleb aga tõdeda, et virtuaalmaailmast on kujunenud kurtide kogukonna ja kuulva ühiskonna üks kohtumispaiku, kus suheldakse sõnas ja pildis ning kus kahaneb tegelikus elus ettetulev keelebarjäär. 


\section{Kommentaarid}

${ }^{1}$ Käsitletud ei ole muid igapäevaseid abivahendeid nagu näiteks valgussignaaliga uksekellad, lapsevalvesüsteemid, vibreerivad äratuskellad jms.

${ }^{2}$ Sõltuvalt keeleoskusest leiab otsija infot muidugi ka teiste rahvuslike kurtide kogukondade ja viipekeelte kohta (nt Prantsuse kurtide üks kodulehekülgi on http:// www.sourds.net; Saksamaa kurtide kohta leiab teavet nt http://www.taubenschlag.de).

${ }^{3}$ Eesti kurtide folkloori kohta vt järgmistest elektroonilistest väljaannetest: Kuuldust-nähtust: Tänapäeva folkloorist IV. http://www.folklore.ee/pubte/kuuldust/ MIX_puu_ei_lange.html_60k, Lemmeleht: Pro folkloristica IX. http:// www.haldjas.folklore.ee/rl/era/nt/PF9/Paales.htm, An Electronical Journal of Folklore. http://www.folklore.ee/folklore/vol27/paales.pdf

\section{Käsikirjad}

EFA I, 47 = Eesti Folkloori Arhiiv. Eesti viipekeelne rahvaluule (materjalikogu käsikiri asub Eesti Rahvaluule Arhiivis kirjandusmuuseumis).

\section{Kirjandus}

ABC Story Steam Engine by Wonsuk Chung (http://www.youtube.com/watch?v=OfiFlhn JMCk\&feature=related -21 . jaanuar 2008).

ASL Name Signs (http://www.handspeak.com/byte/ns/ - 10. detsember 2008).

ASL (american sign language) number story (http://www.youtube.com/watch?v=SZGjmMEjrs\&feature=user - 6. jaanuar 2008).

Bar-Tzur, David. Humor and stories for interpreters: General Deaf humor and musings (http://www.theinterpretersfriend.com/misc/humr/gdh.html-21. jaanuar 2008).

Bar-Tzur, David. Humor and stories for interpreters: The world of Deaf humor (http:// www.theinterpretersfriend.com/misc/humr/world-of-deaf.html - 21. jaanuar 2008).

Bar-Tzur, David. Humor and stories for interpreters: Deaf people in cartoons (http:// www.theinterpretersfriend.com/misc/humr/df-crtuns2.html - 21. jaanuar 2008).

Bell, Alexander Graham. Wikipedia. The Free Encyclopedia (http://en.wikipedia.org/ wiki/Alexander_Graham_Bell - 21. jaanuar 2008).

Berke, Jamie. Deaf Culture - Comic Strips and Cartoons (http://deafness.about.com/ od/deafculture/a/deafcomics.htm - 15. detsember 2007).

Carmel, Simon J 1996. Deaf Folklore. Jan Harold Brunvand (toim). An Encyclopedia. New York \& London, lk 197-200.

Daigle, M. Toons (http://mdaigletoons.com/index.html - 21. jaanuar 2008). 
Keating, Elizabeth \& Mirus, Gene 2003. American Sign Language in virtual space: Interactions between deaf users of computer-mediated video communication and the impact of technology on language practices. - Language in Society 32, lk 693-714. (http://www.ccwf.cc.utexas.edu/ keating/ Publications/ASLVirtSpace.pdf - 8. detsember 2007).

Deaf and Blind (http://deafjoke.tv/wp/wp-content/uploads/2006/09/deaf_blind.jpg 5. jaanuar 2008).

Deaf Cartoon (http://www.deaf4life.co.uk/forum/lofiversion/index.php/t1216.html 5. jaanuar 2008).

Deaf Humor (http://www.lifeprint.com/asl101/pages-layout/humor.htm - 10. jaanuar 2008).

Eesti Kristliku Nelipühi Kiriku kurtide kogudus (http://www.deafestonia.org - 21. jaanuar 2008).

Eesti Kurtide Liit (http://www.ead.ee - 21. jaanuar 2008).

Eesti Kurtide Noorte Organisatsioon ( http://www.ekno.ee - 21. jaanuar 2008).

Eesti Kurtide Spordiliit (http://www.kurtidespordiliit.ee - 21. jaanuar 2008).

Eesti Kuulmispuudega Laste Vanemate Liit (http://www.eklvl.ee - 21. jaanuar 2008).

Eesti Viipekeele Tõlkide Ühing ( http://www.evkty.ee - 21. jaanuar 2008).

I Love You (http://www.lifeprint.com/asl101/images-signs/i_love_you.jpg - 7. jaanuar 2008).

Introduction to eSIGN (http://www.visicast.cmp.uea.ac.uk/eSIGN/Introduction.htm 10. detsember 2007).

Jokes ( http://www.lifeprint.com/asl101/pages-layout/jokes.htm - 10. detsember 2007).

Kruustük, Katrin \& Suurna, Maris \& Siirde, Toomas 2003. Kohlea implantaat - "kuuldeaparaat" kurtidele, Eesti Arst 12, (vt ka http://www.eestiarst.ee/et/export/ showpdf.html?id=24 - 5. jaanuar 2008).

Kurt konn ( http://www.thky.ee/et/varia/konn - 21. jaanuar 2008).

Kurtus ( http://www.ead.ee/kurtus.html - 21. jaanuar 2008).

Le portail d'information sur les sourds (http://www.sourds.net - 8. jaanuar 2008).

Lintrop, Aado 2000. Šamanism ja internet. - Meedia. Folkloor. Mütoloogia. Kõiva, Mare (toim). Tänapäeva folkloorist III. Tartu, lk 101-121.

Mobiilitulkki (http://www.mobiilitulkki.fi - 5. jaanuar 2008).

More Deaf Jokes (http://dww.deafworldweb.org/pub/j/joke.more.html - 15. detsember 2008).

Namesigns (http://www.lifeprint.com/asl101/pages-layout/namesigns.htm - 15.detsember 2007).

Paales, Liina 1999. Miks puu ei kuku maha, miks lind ei lenda ära ehk kurtide viipekeelsest folkloorist. - Kuuldust-nähtust:Tänapäeva folkloorist IV. (http://www.folklore.ee/ pubte/kuuldust/MIX_puu_ei_lange.html_60k - 8. jaanuar 2008). 
Paales, Liina 2001a. Kas viipekeeles saab laulda - ehk kurdipärimuse liikidest eesti viipekeelse rahvaluule näitel. Hiiemäe, Mall \& Labi, Kanni (koost). Klaasmäel: Pro folkloristica VIII. Eesti Kirjandusmuuseum. Tartu, lk 129-148.

Paales, Liina 2001b. Kurtide inimeste elulood: Eeldusi uurimiseks. Jaago, Tiiu (koost). Pärimuslik ajalugu. Tartu Ülikool. Eesti Kirjandusmuuseum. Tartu, lk 143-169. http:/ /www.ead.ee/utoo3.htm

Paales, Liina 2002. Isiku- ja kohamärgid Eesti kurtide märgipärimuses. - Lemmeleht: Pro folkloristica IX (http://www.haldjas.folklore.ee/rl/era/nt/PF9/Paales.htm 8. jaanuar 2008).

Paales, Liina 2004. A Hearer's insight into Deaf Sign Language Folklore. - An Electronical Journal of Folklore (http://www.folklore.ee/folklore/vol27/paales.pdf - 21. jaanuar 2008).

Paavel, Valdeko \& Toom, Regina 1991. Kurtide enesemääramine ja keeled. Akadeemia 3, lk 616-629.

POT - An ABC story by Ken Glickman (http://www.youtube.com/watch?v=SC23a548cj A\&NR - 21. jaanuar 2008).

Pärnumaa Kurtide Ühing (http://www.parnu-kurdid.ee - 15. detsember 2007).

Runnel, Pille 1999. Välitööde võimalikkusest internetis. - Kuuldust-nähtust. Tänapäeva folkloorist IV. Tartu, lk 13-30.

Selective Hearing Aid for Men (http://www.joe-ks.com/archives_sep2003/HearingAid.gif 8. jaanuar 2008).

Sorenson Communications (http://www.sorensonvri.com, http//www.sorensonvrs.com/ what/index.php - 8. jaanuar 2008).

Tallinna Heleni Kool (http://www.helen.tln.edu.ee - 21. jaanuar 2008).

Tallinna ja Harjumaa Kurtide Ühing ( http://www.thky.ee - 21. jaanuar 2008).

Tartu Hiie Kool (http://www.hiie.tartu.ee - 21. jaanuar 2008).

Taubenschlag - das Portal für Gehörlose und Schwerhörige ( http://www.taubenschlag.de - 7. jaanuar 2008).

Telecommunications device for the deaf Wikipedia. The Free Encyclopedia (http://www. en.wikipedia.org/wiki/ Telecommunications_devices_for_the_deaf - 14. detsember 2007).

Video Relay Service Wikipedia. The Free Encyclopedia (http://en.wikipedia.org/wiki/ Video_Relay_Service - 14. detsember 2007).

Video Remote Interpreting Wikipedia. The Free Encyclopedia (http://en.wikipedia.org/ wiki/Video_Remote_Interpreting - 14. detsember 2007).

Spiderman (http://www.iwatchstuff.com/images/2006/06/spiderman-3-poster.jpg 6. jaanuar 2008).

What are Cochlear Implants? (http://video.about.com/deafness/Cohlear-Implants.html -6. jaanuar 2008).

Woolley, Maggie 2000. Mõtle sellele. Elu kurdina. Koolibri. 


\title{
Summary
}

\section{Deaf Community, Sign Language and Sign Lore in Technological Environments Supporting the Visual Aid}

\author{
Liina Paales
}

Key words: Internet, deaf, deaf folklore, hearing devices, hearing impairment, sign language, visual technologies

The article discusses the specific devices for the deaf people, and sign language and deaf lore in the new technological situation. There are different types of hearing aids supporting the concept of the deaf as the disabled who must be cured from their deafness and taught to communicate orally with the hearing world. Today there are many modern devices that support the visual aid, which is more comfortable for the deaf. In fact, for the deaf who are more cultured there is nothing to be cured or healed. They are sceptical about the emergence of any new medical device (e.g., cochlear implant), which aim seems to be turning a deaf into a hearing person.

The deaf have become adapted to new technologies for their community's needs and use their language, culture and folklore in new environments, such as the Internet. Various telecommunication devices have made the direct translation of sign language possible. The deaf have become used to communicating on cell phones, videophones, web cameras, etc.

Sign language communities have discovered the virtual space to share their culture and folklore among the community members and with the hearing world. There are many examples of deaf lore available on the Internet, mostly from among American deaf folklore. Many stories have been translated from sign language into verbal language, but one can also encounter authentic sign language texts in the form of video clips, sometimes with voiceover or subtitles. Virtual space is a wonderful place to present deaf people's own folklore, which has also been called sign lore. Fine examples of sign lore are ABC stories and number stories, also some popular signs like 'I Love You' sign. Deaf comics are also part of deaf lore and culture. Deaf comics characterise the cultural side of deafness from a humorous viewpoint.

New technologies offer the deaf good opportunities for expressing their culture and promoting sign language and also for being in touch with other community members and with the hearing people. 